\title{
CONTRASTIVE INTERLANGUAGE ANALYSIS OF EVIDENTIALITY IN PHD DISSERTATIONS ${ }^{1}$
}

\author{
Mustafa Yildiz and Ümit Deniz Turan
}

\begin{abstract}
The present study investigates evidentiality in its broadest sense (Chafe 1986) in $\mathrm{PhD}$ dissertations as a genre of academic writing. For this purpose, Chafe's taxonomy (1986), revised by Ifantidou (2001), has been used as a framework in order to analyze three different groups of datasets, including one group of native speakers of English and two groups of non-native speakers: a group of Turkish speakers of English and the other non-native speakers with different L1 backgrounds. The texts of these three groups are examined in order to find out whether the native language of the participants is a factor in the choice of evidential markers. The results show that the native speakers of English use evidential markers more frequently compared to the non-native authors. In terms of the Native Language/Interlanguage comparison in Contrastive Interlanguage Analysis (Granger 1996, 1998), the overall use of evidentiality reveals that non-native authors do not show native-like features in the use of evidentiality. In terms of the Interlanguage/ Interlanguage comparison, Turkish authors of academic texts differ from the authors with various native language backgrounds in terms of the use of evidentiality.
\end{abstract}

\section{Keywords}

evidentiality, epistemic modality, contrastive interlanguage analysis, academic discourse

\section{Introduction}

English has become Lingua Franca among academics to convey the results of scientific research, as evident from the fact that a vast majority of scientific journals publish academic works in English. By publishing their articles in English, researchers have a better chance to reach the international community of researchers. With this in mind, the non-native speaking researchers should pay attention to the characteristics of academic discourse. An important characteristic of academic discourse is evidentiality, which pertains to the notions of the source of knowledge and the degree of reliability of the propositions.

The present study investigates the use of evidentiality under the broad view in the 'discussion' or 'discussion and conclusion' chapters of $\mathrm{PhD}$ dissertations written in English by native and non-native speakers. The main purpose is to explore how $\mathrm{PhD}$ candidates express themselves in terms of evidentiality. By doing so, this study aims to illuminate to what extent certainty/uncertainty is 
conveyed in the relevant sections of the dissertations analyzed and how this knowledge is attained. Any potential differences in the use of evidentiality between native and non-native speakers are also addressed in the study.

The rest of this paper is organized as follows: In Section 2, evidentiality is presented. The previous studies on the use of evidentiality in different genres and academic discourse are discussed in Section 3. The method of the study, the data and taxonomy of evidentiality used in the study are given in Section 4 . The results of the study and the discussion of the results take part in Section 5. Section 6 is devoted to the conclusion drawn on the basis of the findings.

\section{Evidentiality}

Evidentiality as "the linguistic marking of evidence" concentrates on whether speakers/writers have seen, heard or inferred what they produce as linguistic performance (Bednarek 2006: 635). The definition of evidentiality goes back to Boas (1911), in which Goddard (1911) notes that some knowledge towards the source of information such as inference and sensory perception is coded by means of some grammatical particles (ibid.: 124). Evidentiality is the information source that refers to how speakers/writers attain certain knowledge (Aikhenvald 2004: 1), its linguistic codification (Mushin 2000, Davis et al. 2007, Cornilie 2009), "the kinds of evidence a person has for making factual claims" (Anderson 1986: 273).

Languages vary in terms of marking evidentiality, providing options for the grammatical or lexical codification of the source of knowledge and how it is attained. Languages have verbal affixes, clitics, and/or separate lexical means to express evidentiality as the source of knowledge. Some languages like Turkish have a bound suffix, $-m I$ ş, which marks unwitnessed events, so the source of knowledge is attributed to another agent or information based on visual, inferential, or other type of evidence (Aksu-Koç \& Slobin 1986, Aksu-Koç 1988, 2000, Johanson 2000, among others). Wintu, a language spoken in Northern California is an extreme case in the sense that " $[\mathrm{t}] \mathrm{h}$ W Wintu never say it is bread. They say, 'It looks-to-me bread' or 'It feels-to-me bread' or 'I-have-heard-it-tobe bread' or 'I-infer-from-evidence-that-it-is-bread' or 'I-think-it-to-be bread', or, vaguely and timelessly, 'according-to-my-experience-be bread"' (Lee 1959: 137). The way of expressing the source of the information the speakers/writers use in Wintu shows that the Wintu language expresses evidentiality somewhat indirectly. Evidentiality can be considered as two types: Direct and Indirect. In the direct evidential category, the speaker has direct access to the source of knowledge through first-hand visual or auditory evidence, while in indirect evidence the speaker has deduced, inferred the knowledge or heard it from 
others, i.e. hearsay or quotative. Johanson (2000), who analyzes evidentials in Turkic, uses the term 'indirectives' for the categories hearsay, inferential, and admirative. As opposed to those languages that mark evidentiality by affixes, English does not have a separate bound morpheme marking for evidentiality, but it makes use of expressions such as 'it seems that', 'reportedly', 'it is said that', etc.

Evidentiality is associated with epistemic modality in the literature. Evidentiality, "the functional category that refers to the perceptual and/or epistemological basis for making a speech act" (Cornilie 2009: 45), not only codes how the knowledge is acquired, but also expresses to what extent the speaker/writer assigns the degree of reliability (Mushin 2001: 1362, Bednarek 2006: 635, McCready \& Ogata 2007: 149, Clark 2010: 157).

According to Mushin (2000: 932), "evidentiality is a deictic category" as it attributes some knowledge to the source of information and its degree of factual status. Palmer (2001) suggests the term 'propositional modality' for evidentiality and epistemic modality; he states that "with epistemic modality speakers express their judgments about the factual status of the proposition, whereas with evidential modality they indicate the evidence they have for its factual status" (ibid.: 8 ). The source of knowledge and its reliability assessment are dealt with either separately or together. The literature adopts three different approaches to how evidentiality and epistemic modality are integrated into each other: disjunction, inclusion, and overlap (Dendale \& Tasmowski 2001: 341-342, Cornilie 2009: 47).

These three different perspectives define evidentiality in different ways. On the one hand, disjunction, i.e. the narrow view, refers to evidentials expressing only the source of the knowledge or information (Kim 2005, Hsieh 2008, Clark 2010). In other words, according to the narrow view, evidentiality is used to restrictively inform the reader/listener only about the source of the evidence and the way in which knowledge is attained. Instead of an overlapping relationship between evidentiality and epistemic modality, there is a conceptual difference between them in the narrow view. The following two examples from Clark (2010: 140-141) illustrate the difference between these two terms.

(1) Tony Blair must be happy.

(2) Tony Blair said he is relatively happy.

Example (1) above is directly related to epistemic modality and informs the interlocutor about the extent to which the writer/speaker is confident in his/her proposition. In (2), however, the interlocutor is informed not about the writer's/ speaker's degree of confidence but the source of information. 
On the other hand, Chafe (1986: 262-271) and some recent research (Koutsantoni 2005, Bednarek 2006, Fetzer 2014) support the broad view, which not only refers to the source of the knowledge or information but also evaluates the degree of certainty in the proposition. The discourse reveals to what extent the proposition by the speaker/writer is confident and reliable. Likewise, Matlock (1989) defines evidentials as "linguistic units comprising part of epistemic modality, code a speaker's source of information, and some degree of certainty about that information" (ibid.: 215). In inclusion, evidentiality and epistemic modality are "two concepts being regarded as falling within the scope of the other" (Dendale \& Tasmowski 2001: 342). Therefore, if the broad view of evidentiality is adopted in a study, it not only refers to the source of the knowledge, but also to the reliability of the writer's/speaker's knowledge. Plungian (2001) argues that evidentiality is included in epistemic modality in every case; however, the vice versa is not necessarily the case.

While an evidential supplement can always be seen in an epistemic marker, the opposite does not always hold: not all evidential markers are modal in that they do not all necessarily imply an epistemic judgment. More generally, one can say that the reliability of information usually depends on how it was obtained: visual information is thought to be most reliable, whereas mediated information is the least reliable (Plungian 2001: 354).

Claiming that "all evidential markers are said to be essentially epistemic, while not all epistemic markers are considered cases of evidentiality", AlonsoAlmeida and Cruz-Garcia (2011: 60) support this suggestion of Plungian (2001). In a similar vein, Jeschull and Roeper (2009: 107) state the "elementary distinction" between evidentiality and epistemic modality by remarking that "while evidence can naturally produce some degree of certainty, a degree of certainty cannot produce nor should be taken as a form of evidence". As seen in the quotations, the way the speaker/writer attains the knowledge affects to what extent the knowledge is reliable. Even though the knowledge may be reliable, this reliability does not necessarily inform the listener/reader about how the knowledge is obtained.

The third perspective advocates that there is an overlapping parallelism between evidentiality and epistemic modality by means of inferential evidentiality, "the evidence as based upon reasoning" (Auwera \& Plungian 1998: 85), which is a sub-type of evidentiality and has an epistemic function. They note that "inferential evidentials often receive an English translation with epistemic must. Inferential evidentiality is thus regarded as an overlap category between 
modality and evidentiality" (ibid.: 86). In line with Auwera and Plungian (1998), Faller (2002: 10) advocates that inference is not only "a way of 'acquiring' information through reasoning" but also is a way of pointing out "the speaker's judgment that the proposition expressed is necessarily true". Therefore, both evidentiality and epistemic modality consist of inference as a subset.

The source of knowledge is both directly the scope of evidentiality and implicitly the key concern of the epistemic modality. Chafe (1986: 262) proposes that "knowledge may be regarded by a speaker (or writer) as more or less RELIABLE (or valid)". According to Chafe, evidential markers qualify the status of the information. Writers or speakers attribute a degree of reliability to their written or spoken outputs through markers of evidentiality (ibid.: 262-263). However, reliability markers do not inform the hearer/reader about the source of knowledge, i.e. evidentiality (ibid.: 266). Likewise, De Haan (1999: 85) emphasizes that "epistemic modality evaluates evidence and on the basis of this evaluation assigns a confidence measure to the speaker's utterance. This utterance can be high, diminished, or low".

Evidentiality as a linguistic system is studied from different perspectives, such as the acquisition of evidentiality in various languages (Aksu-Koç 1988, 2000, O’Neill \& Atance 2000, Ifantidou 2005, Fitneva 2008, Oztürk 2008, Jeschull \& Roeper 2009, Aydın \& Ceci 2009, Rett \& Hyams 2014, Koring $\&$ De Mulder 2015); the use of evidentiality in a variety of genres in different languages, such as English newspapers (Bednarek 2006), diachronic analysis of newspaper articles from 1993-2005 (Clark 2010), the aspect of illocution (Sbisa 2014), Chinese newspaper reports in terms of subjectivity and objectivity (Hsieh 2008), Greek cultural characteristics and academic writing (Koutsantoni 2005), English academic discourse (Fetzer 2014, Yang 2014), a comparative study of the use of research articles by Chinese and English native speakers (Yang 2012), and reporting evidentials in English research articles (Yang 2013) (see also Fetzer $\&$ Oishi 2014). There is also research, albeit relatively more limited in number, which analyzes evidentiality in spoken data (interview corpus in French-English bilingual discourse in King \& Nadasdi 1999, telephone conversations in Korean in Kim 2005, political debates in English in Berlin \& Prieto-Mendoza 2014).

\section{Previous literature on the use of evidentiality in different genres}

A brief review of literature on evidentiality in different genres is provided in this section.

Berlin and Prieto-Mendoza (2014) analyze the political debates that took place before the 2010 US Midterm Congressional elections. Markers of deduction appear as the most frequent evidential elements in this spoken database. However, 
markers of sensory evidence are very few in number in the entire data. This is because the speakers used these to attack their rivals and they preferred to choose less reliable markers in order to avoid potential risks of more robust evidence.

In Hsieh (2008), the news requiring objectivity such as politics and business reports frequently consist of reportative evidential markers; however, sensory evidentials come into view more often in local news. The context and content of the news act as the selective elements in the expression of evidentiality.

Clark (2010) analyzes two different newspaper corpora to reveal whether any difference occurs in terms of the expression of evidentiality over a thirteenyear period. Increased use of evidentiality and an alteration towards the speculation-based knowledge reports and hearsay evidence in 2005 quality papers stand out as the most striking findings.

\subsection{Evidentiality in academic discourse}

Chafe (1986: 262) conducts a study in which the casual conversations and the academic written data are compared with regard to the frequency of evidential markers. The results show that the proportion of the overall evidential markers in conversational English and in academic writing is almost alike. The proportion of the evidential markers in academic writing, 0.64 per 1,000 words, slightly outnumbers the proportion of evidential markers in conversational English with 0.60 occurrences per 1,000 words. Even though there is not much difference between academic writing and conversational English in terms of the overall frequency of evidential markers, there is a disparity in the occurrence of some specific kinds of evidentials. Chafe explains these disparities between the spoken and written data in terms of two differences. Firstly, the writer is at an advantage of having enough time to plan what to write and to edit what is written. It is worth reminding that a writer has a chance to take into consideration some kinds of the epistemological assessments a speaker cannot have. Secondly, while the speaker experiences a direct and face-to-face interaction with the interlocutor, the writer has to complete the writing process some time before the text reaches the reader. Hence, the speaker has a chance to revise and update some of his utterances to fulfill the listeners' expectations.

Yang (2012) compares and contrasts the native speakers of English and the native speakers of Chinese to determine whether any difference occurs in their evidential use in research articles. It is found that while reporting and inferring evidential markings are the most frequently encountered evidential items, belief and sensory evidentials are the least frequent evidential items in both of the databases. While the most frequent use of evidential markers appears in the introduction parts, the data and method sections consist of evidential markers the least in number. 
Koutsantoni (2005) compares Greek native speaker authors with the English native speaker authors in terms of their use of the degree of certainty. It is evaluated that a greater number of certainty markers appear in the Greek writers' research articles and this is considered to be the result of some features of Greek culture, such as high power distance, high uncertainty avoidance, and collective nature.

Alonso-Almeida and Cruz-Garcia (2011) examine the abstract sections of medical research articles to determine whether may and might can be used as the grammatical markers of evidentiality. The modal may shows a dominant occurrence compared to the modal might with less than 5 per cent of occurrences. While may is used with the meaning of both epistemic modality and evidentiality, might denotes just epistemic meaning.

Fetzer (2014) investigates the patterned co-occurrences of perception verbs seem and appear in terms of inferential evidentiality and of the modal auxiliaries may, can, and must with argumentative markers in written academic discourse. While the sensory perception verb seem appears as the most restrictive one with argumentative markers, may is the least restrictive co-occurrence item. The modal auxiliaries may and can tend to co-occur with the adverbs like significantly and well; however, must never takes place with any adverbs and is the least frequently encountered modal auxiliary in the data.

The present study investigates the use of evidentiality under the broad view in the 'discussion' or 'discussion and conclusion' chapters of $\mathrm{PhD}$ dissertations written in English by native and non-native speakers. The aim is to reveal the linguistic realizations of expressing the knowledge, the source of information and certainty/uncertainty in the relevant sections of dissertations. Furthermore, these linguistic realizations of evidentiality are compared in terms of the L1 background of the participants and the extent of the similarity between the texts of native and non-native speakers.

\section{Method}

The present study adopts Contrastive Interlanguage Analysis (CIA) as the research methodology (Granger 1996: 43-44, 1998: 12-14). According to Granger $(1996,1998)$, a comparison between the two or more major groups can be carried out based on:

1. NL (Native Language) vs. IL (Interlanguage)

2. IL (Interlanguage) vs. IL (Interlanguage)

The former refers to a comparison between the native language and interlanguage while the latter refers to the comparison of different interlanguages. According to Granger (1996: 43-44, 1998: 12-14), the NL/IL comparison 
examines the non-nativeness of the learner language. This helps to reveal the different frequency of use of particular lexical items and the structures which are more frequent or less frequent at times, by contrasting the results with a native speaker corpus/database as a control group. It should be noted that researchers should keep the comparability of the text types in mind. Because of the style-sensitiveness of many language features, it is vital to utilize the same genres as the content of the control corpora/databases. Different texts such as news magazines and reports based on scientific research do not have the same characteristics of persuasiveness and reliability due to the fact that they require different linguistic features. Comparing two different databases, including data of genres irrelevant to each other, would be a major drawback failing to offer an explanation for the distinction between native and non-native speakers. Additionally, Granger (2015: 8) clarifies the reason of using a native speaker corpus/database as a control group as the acceptance of native speaker data being the ultimate attainment of learning a foreign or second language.

The IL/IL comparison requires the comparison of interlanguages of the same language or different ones. Different varieties such as age, proficiency level, L1 background, task type, learning setting, medium, etc. can be used to investigate their effect on the learner outputs (Granger 1998: 13-14, 2015: 8).

The present study reflects both the features of the NL vs. IL comparison and the IL vs. IL comparison within itself, as it is based on the analysis of three databases, through which the researchers investigate the use of evidentiality in the dissertations of native and non-native academic writers of English. The focus is on whether the Native speakers of English (NSE), the Native Speakers of Turkish (NST) and the speakers with various L1 backgrounds differ significantly with regard to their use of evidentiality. On the one hand, the present study compares interlanguages of English with different L1 backgrounds with the native speaker database as the control group; therefore, it fulfills the requirement of the NL vs. IL comparison. On the other hand, it compares native speakers of Turkish and the speakers with various L1 backgrounds to test the variety of different L1 backgrounds. Hence, the present study also meets the expectations of the IL vs. IL comparison. To validate this, the CIA approach (Granger 1996, 1998) constitutes the main research methodology of the present study by its very nature.

\subsection{Taxonomy used in the present study}

As opposed to the morphologically-marked evidential systems in some languages of the World (Aksu-Koç \& Slobin 1986, Johanson \& Utas 2000, inter alia), English uses lexical evidentiality marking. Chafe (1986) presents 
comprehensive data about English lexical markers expressing evidential meaning, which was further developed by Ifantidou (2001). Both Chafe (1986) and Ifantidou (2001) address the issue under the broad view in which not only the source of the knowledge, but also the speaker's degree of certainty are taken into consideration. These studies are taken as the framework of the analysis in this study.

\begin{tabular}{|c|c|c|c|c|c|c|c|}
\hline $\begin{array}{l}\text { Markers of } \\
\text { reliability }\end{array}$ & $\begin{array}{c}\text { Markers } \\
\text { of belief }\end{array}$ & $\begin{array}{c}\text { Markers of } \\
\text { induction }\end{array}$ & $\begin{array}{c}\text { Markers } \\
\text { of hearsay }\end{array}$ & $\begin{array}{c}\text { Markers } \\
\text { of } \\
\text { deduction }\end{array}$ & \begin{tabular}{|c|} 
Markers \\
of sensory \\
evidence
\end{tabular} & $\begin{array}{c}\text { Markers of } \\
\text { matching } \\
\text { knowledge } \\
\text { against } \\
\text { verbal } \\
\text { resources } \\
\end{array}$ & \begin{tabular}{|c|} 
Markers of \\
matching \\
knowledge \\
against \\
expectations
\end{tabular} \\
\hline certainly & I think & must & people say & should & I see & kind of & of course \\
\hline undoubtedly & I guess & obvious & they say & can & I hear & about & in fact \\
\hline surely & I suppose & seem & $\begin{array}{l}\text { I've been } \\
\text { told }\end{array}$ & could & I feel & sort of & actually \\
\hline by definition & I know & evidently & $\mathrm{X}$ told me & would & looks like & & at least \\
\hline exactly & I suspect & seems to & $\mathrm{X}$ said & presumably & sounds like & & even \\
\hline invariably & & must be & $\begin{array}{l}\text { supposed } \\
\text { to }\end{array}$ & & feels like & & only \\
\hline literally & & must have & apparently & & it tastes & & but \\
\hline particularly & & so & it seems & & smells like & & however \\
\hline specifically & & I deduce & $\begin{array}{c}\text { have been } \\
\text { said }\end{array}$ & & & & nevertheless \\
\hline basically & & consequently & I hear & & & & oddly enough \\
\hline essentially & & & he is said & & & & \\
\hline generally & & & $\begin{array}{l}\text { he is } \\
\text { reputed }\end{array}$ & & & & \\
\hline primarily & & & allegedly & & & & \\
\hline maybe & & & reportedly & & & & \\
\hline probably & & & $\mathrm{X}$ tells me & & & & \\
\hline \multicolumn{8}{|l|}{ might } \\
\hline \multicolumn{8}{|l|}{ may } \\
\hline \multicolumn{8}{|l|}{ possibly } \\
\hline \multicolumn{8}{|l|}{ perhaps } \\
\hline \multicolumn{8}{|l|}{$\begin{array}{c}\text { in some } \\
\text { sense }\end{array}$} \\
\hline \multicolumn{8}{|l|}{ normally } \\
\hline \multicolumn{8}{|l|}{ virtually } \\
\hline obviously & & & & & & & \\
\hline
\end{tabular}

Table 1: Taxonomy of the evidentiality markers 
According to Chafe (1986: 263), the way the knowledge is attained is named as modes of knowing, i.e. through belief, induction, hearsay, and deduction. Ifantidou (2001: 6-7), on the other hand, divides the source of knowledge into four types: observation, hearsay, inference, and memory.

Based on Chafe's taxonomy (1986) revised by Ifantidou's (2001), Table 1 illustrates the taxonomy of the evidentiality markers to be analyzed in the present study.

\subsection{The Data}

The study is based on the analysis of $89 \mathrm{PhD}$ dissertations, forming three different databases, written by native and non-native speakers of English between the years of 2009 and 2016. Each of these three databases is compiled based on the L1 background of the authors: the Native Speakers of Turkish Database (NSTd), the Native Speakers of English Database (NSEd), and the World English Database (WEd). Each of the NSTd and the NSEd consists of 30 dissertations; and WEd 29 dissertations. Figure 1 shows the distribution of dissertations according to the authors' L1 background.

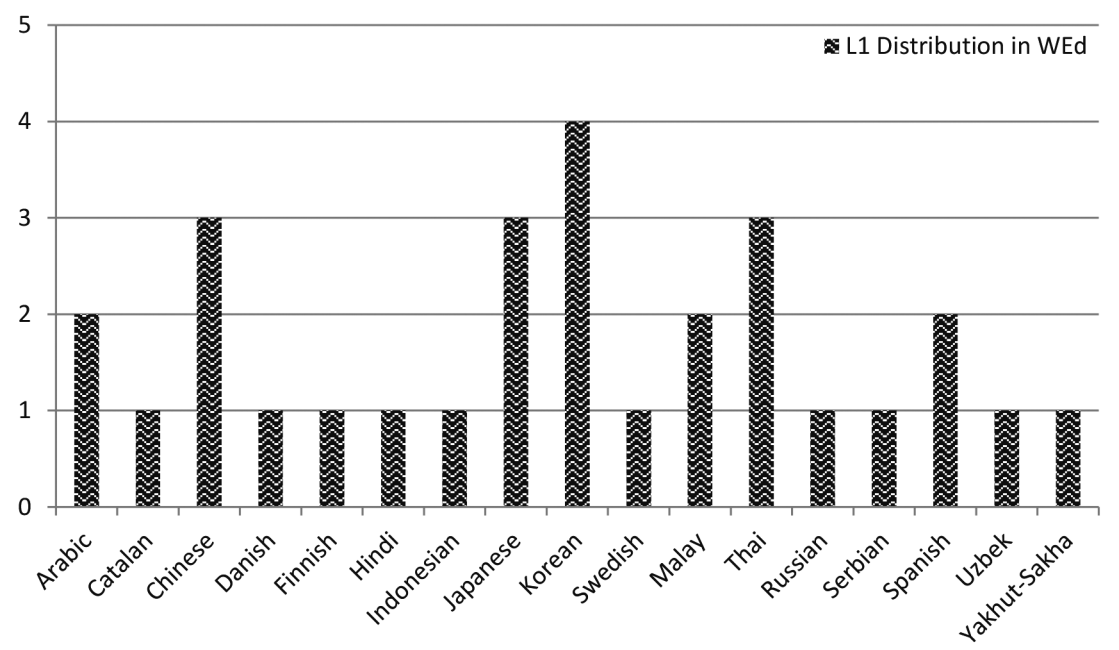

Figure 1: Distribution of dissertations according to authors' L1 background

There are 17 different L1s in the WEd. Catalan, Danish, Finnish, Hindi, Indonesian, Swedish, Russian, Serbian, Uzbek and Yakhut (Sakha) are the L1s, for each of which there is only one author. There are two authors with each of 
Arabic, Malay and Spanish L1s; three authors with each of Chinese, Thai and Japanese L1s; and four authors with Korean L1s.

\subsection{Log-likelihood calculator}

A Log-likelihood calculator is used to reveal whether these three databases differ significantly in terms of the frequency of use of the evidential markers. The test makes calculations regarding the raw frequencies of an item in each of the two databases and the overall sizes of these two databases (e.g. NSEd vs. NSTd/ NSEd vs. WEd/NSTd vs. WEd). In line with the citation in the Notes section ${ }^{2}$ (Rayson et al. 2004) the cut-off value of the present research is adopted as 15.13 in each of the Log-likelihood calculations.

\section{Results and discussion}

\subsection{Overall use of evidentiality}

In general, as shown in Figure 2, the use of evidentiality in the NSEd is more frequent than in the other two non-native databases. The NSTd ranks second while the least frequent use of evidentiality appears in the WEd. Apart from the overall use of evidential markers, markers of reliability, deduction and matching knowledge against expectations stand out with frequent occurrences in each of the three databases. The rest of the evidential types except markers of induction hardly ever occur in each of these databases.

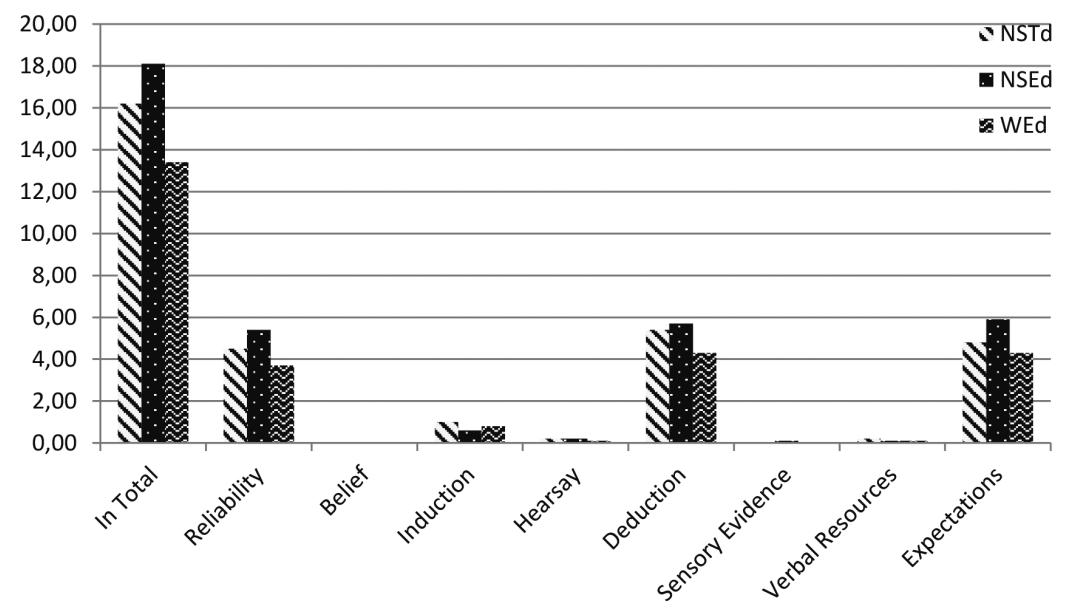

Figure 2: Normalized frequency distribution of evidentiality (per 1,000 words) 
The following conclusions are reached when the three databases are taken into consideration. Firstly, the use of evidential markers by the native English authors is more frequent than that by the non-native authors. Secondly, the use of markers of reliability, deduction, and matching knowledge against expectations are very frequent in the dissertations. Both the native and non-native databases consist of a considerable amount of use of these types. It can be stated that the use of these types is a natural result of the academic genre. This is because the writers of academic discourse must persuade their readers and they must provide reliable information in doing so. These writers must also generate new knowledge by making deductions on evidence provided by existing knowledge. Thirdly, low use of markers of belief, sensory evidence, hearsay and matching knowledge against verbal resources in each of the three databases is in line with the nature of the academic genre. The foundations of academic discourse are not based on subjective characteristics as observed in hearsay, belief and sensory evidence; but rather based on objective observations free from subjective sensory evidence.

\begin{tabular}{|l|c|c|c|c|c|c|}
\hline & NSEd & NSTd & WEd & $\begin{array}{c}\text { LL Ratio } \\
\text { for NSEd- } \\
\text { NSTd }\end{array}$ & $\begin{array}{c}\text { LL Ratio } \\
\text { for NSEd- } \\
\text { WEd }\end{array}$ & $\begin{array}{c}\text { LL Ratio } \\
\text { for NSTd- } \\
\text { WEd }\end{array}$ \\
\hline $\begin{array}{l}\text { Normalized } \\
\text { occurences }\end{array}$ & $\% 18.1$ & $\% 16.2$ & $\% 13.4$ & $+\mathbf{1 7 . 1 4}$ & $+\mathbf{1 5 9 . 0 6}$ & $+\mathbf{5 5 . 5 1}$ \\
\hline
\end{tabular}

Table 2: Frequency analysis of overall use of evidentiality

As illustrated in Table 2, the authors in the non-native databases do not show native-like features in the overall use of evidentiality (17.14-159.06 LL values; $\mathrm{p}<0.0001$ ). In terms of the Native Language/Interlanguage comparison, both the authors in the NSTd and the ones in the WEd exhibit different characteristics from the authors in the NSEd as discussed below. As for the Interlanguage/ Interlanguage comparison (Granger 1998: 13-14, 2015: 8), the overall use of evidentiality in the non-native databases does not resemble each other (55.51 LL value; $\mathrm{p}<0.0001)$. They show different characteristics.

The native speakers of English make use of evidentiality more frequently compared to the non-native speakers. This may be due to the fact that the native speakers of English tend to hedge or boost more of their propositions in the text. As for the non-native authors, compared to the authors with various L1 backgrounds, the native speakers of Turkish have a tendency to increase/lower their commitment to the proposition.

In addition to the frequency of use of evidentiality, markers of reliability, deduction, and matching knowledge against expectations are frequently used 
by both the native and non-native authors. The fact that these evidential types are common and high in number in each of these three databases may be that academic writing conventions are similar across cultures in this respect.

Contrary to these extensively-used evidential types, quite low use of markers of belief, sensory evidence, hearsay and matching knowledge against verbal resources in each of these three databases suggests that academic writing is very selective in its components. These types do not serve for the purpose of academic writing and are against its nature due to the subjectivity characteristics of these markers, as stated above.

5.2 Use of markers of reliability

\begin{tabular}{|c|c|c|c|c|c|c|}
\hline & NSEd & NSTd & WEd & $\begin{array}{c}\text { LL Ratio } \\
\text { for NSEd- } \\
\text { NSTd }\end{array}$ & $\begin{array}{c}\text { LL Ratio } \\
\text { for NSEd- } \\
\text { WEd }\end{array}$ & $\begin{array}{c}\text { LL Ratio } \\
\text { for NSTd- } \\
\text { WEd }\end{array}$ \\
\hline $\begin{array}{c}\text { Normalized } \\
\text { occurences }\end{array}$ & $\% 5.4$ & $\%_{0} 4.5$ & $\%_{0} 3.7$ & +13.99 & +73.41 & +16.24 \\
\hline
\end{tabular}

Table 3: Frequency analysis of markers of reliability

Table 3 shows that with regard to the Native Language/Interlanguage comparison as a part of Granger's Contrastive Interlanguage Analysis (1998: 12-14), the NST authors show native-like features in terms of the use of markers of reliability (13.99 LL value). Their use of markers of reliability shows similarity with the native authors' use. However, the authors' interlanguages in the WEd show different characteristics from the NSE authors' use of markers of reliability ( $73.41 \mathrm{LL}$ value). When we compare the Interlanguage/Interlanguage data, different L1 backgrounds of these authors in the non-native databases bring about a differentiation between these non-native databases with regard to the use of markers of reliability. That is to say, the non-native authors do not share common features in use of markers of reliability (16.24 LL value).

The use of markers of reliability is considerably frequent in each of these three databases. According to Chafe (1986: 264), "not all knowledge is equally reliable". While some of the information is more reliable, some is less. Markers of reliability in the text increase or decrease the author's commitment to the truth of the proposition. The results may indicate that the NSE and the NST authors equally take on responsibility for their texts.

All groups show low speaker commitment with regard to the use of markers of reliability, almost three quarters are composed of may and might in each database. The authors tend to conjecture on their findings as a strategy in discussion sections in academic writing. The normalized frequency of may and might forms 78.29 per cent of the overall use of markers of reliability in the NSTd. This size 
is equal to 75.54 per cent of markers of reliability in the NSEd. The size of may and might in the overall markers of reliability drops down to 72.56 per cent in the WEd. This, on its own, is enough to suggest that markers of reliability are used in each of these three databases to "indicate the writer's decision to withhold complete commitment to a proposition, allowing information to be presented as an opinion rather than accredited fact" (Hyland 2005b: 178).

The following extracts illustrate the use of modals may and might as reliability markers to add low probability to the proposition.

...This may be due to the fact that these structures are not used in adult spoken language frequently, which is in line with several studies showing that object RCs are less frequent than subject $R C$ s.

As a matter of its nature, academic writing avoids the use of strong, assertive propositions. The authors tend to hedge by toning down their propositions by means of some reliability markers, such as may. As shown in Example (3), the author comes up with a possible reason for some structures infrequently used in adult language.

...Turkish-English bilingual children performed less successfully both in comprehension and production compared to Turkish monolingual children. We conjecture that this might be due to the fact that they do not receive any formal input (i.e., literacy education or instruction) in Turkish language.

Similarly to may, the use of might also adds low possibility meaning to the proposition in Example (4). The author states a reason for why monolingual children are more successful in comprehension and production compared to bilingual children. The use of the verb to conjecture, by itself, reflects the author's assumption for the potential reason s/he thinks of. In addition to the verb to conjecture, the modal might in the same sentence creates a highly unreliable proposition.

\subsection{Use of markers of belief}

\begin{tabular}{|c|c|c|c|c|c|c|}
\hline & NSEd & NSTd & WEd & $\begin{array}{c}\text { LL Ratio } \\
\text { for NSEd- } \\
\text { NSTd }\end{array}$ & $\begin{array}{c}\text { LL Ratio } \\
\text { for NSEd- } \\
\text { WEd }\end{array}$ & $\begin{array}{c}\text { LL Ratio } \\
\text { for NSTd- } \\
\text { WEd }\end{array}$ \\
\hline $\begin{array}{c}\text { Normalized } \\
\text { occurences }\end{array}$ & $\% 0.00$ & $\% 0.00$ & $\% 0.00$ & +4.95 & +1.88 & -1.74 \\
\hline
\end{tabular}

Table 4: Frequency analysis of markers of belief 
As demonstrated in Table 4, in terms of the Native Language/Interlanguage comparison, the non-native databases show native-like features in terms of the use of markers of belief. Their use of markers of belief shows similarity with the native authors' use of markers of belief. As for the Interlanguage/Interlanguage comparison, non-native authors seem to be very much alike.

The findings devoted to the use of markers of belief in each of the three databases show parallelism with the nature of academic writing. The markers of belief in Table 1 are frequently encountered in neither form of the academic genre. In consideration of the findings devoted to the markers of belief both in the present study and in the relevant research, it can be inferred that the use of markers of belief is not in tune with academic writing. These markers do not serve for the author's purpose to convince the reader about the accuracy of the proposition. They reduce the reliability of the research as well. Namely, the presentation of the findings with the use of markers of belief fails to convince the audience.

As for to what extent these markers of belief denote reliability, it can be expressed that all of the markers except I know consist of writers' belief with a low degree of reliability. They refer to less reliable sources of information; therefore, the knowledge presented is evaluated as less valid on the interlocutor.

... If we give weight to pupils' wishes - as I think we should - CLIL reports are worth embarking on.

As can be seen in Example (5) above, the assertion is based on opinion. I think indicates that the author is not sure of whether they should give weight to pupils' wishes or not.

As a mode of knowing, belief is expressed by Chafe (1986: 266) as a source of knowledge, for which the availability of the evidence is neglected. The use of I think in Example (5) above bases the author's arguments on his/her belief or ideas. Interestingly, defining the modes of knowing, Chafe underlines that knowledge based on belief is conveyed through the expressions such as I think, I guess and I suppose in conversational English. The use of $I$ think is not an ordinary habit of academic writing (ibid.: 266). Apart from these, by discussing the mitigating effect of I think on speaker's/writer's assertions, Berlin (2008) argues "the simple insertion of $I$ think mitigates the force of an assertion while simultaneously alleviating the speaker of complete culpability, or commitment to the truth value of the assertion" (ibid.: 377 ). The use of I think functions as the inclusion of a speaker's own reflection as the source of knowledge transmitted 
to the interlocutor (Hassler 2015: 183). However, academic writing requires knowledge based on evidence instead of a speaker's own estimation.

Some reasons could be offered for why these markers of belief are minimally used in the data. For example, the source of the knowledge "for belief is problematic" (Chafe 1986: 263). There is no basis for how the author attains the knowledge. The author shares his/her opinion or belief lowering the reliability in the text. Even though opinion or belief as a mode of knowing is valuable in some other genres, e.g. in newspaper articles it would attract a vast audience, it does not work in the academic genre to persuade the reader of the scientific validity of the text. The audience of scientific texts has expectations for the evidence supported through scientific processing instead of the author's intuition. Consequently, markers of belief do not add any contribution to the scientific validity of the academic texts except lowering their reliability.

\subsection{Use of markers of induction}

\begin{tabular}{|c|c|c|c|c|c|c|}
\hline & NSEd & NSTd & WEd & $\begin{array}{c}\text { LL Ratio } \\
\text { for NSEd- } \\
\text { NSTd }\end{array}$ & $\begin{array}{c}\text { LL Ratio } \\
\text { for NSEd- } \\
\text { WEd }\end{array}$ & $\begin{array}{c}\text { LL Ratio } \\
\text { for NSTd- } \\
\text { WEd }\end{array}$ \\
\hline $\begin{array}{c}\text { Normalized } \\
\text { occurences }\end{array}$ & $\% 0.6$ & $\% 01$ & $\% 0.8$ & $\mathbf{- 2 3 . 6 8}$ & -11.15 & +4.55 \\
\hline
\end{tabular}

Table 5: Frequency analysis of markers of induction

Table 5 demonstrates that as for the Native Language/Interlanguage comparison, the authors in the WEd show native-like features in terms of the use of markers of induction (11.15 LL). Their use of markers of induction shows similarity with the native authors' use of these markers. However, the authors' interlanguages in the NSTd show different characteristics from the native authors' use of markers of induction (23.68 LL). As for the Interlanguage/Interlanguage comparison, non-native authors highly resemble each other (4.55 LL).

The present study investigates the discussion parts of dissertations. In this part, the researchers are expected to offer some potential reasons for the present results. As the name implies, the reasons offered are potential, namely possible, and subjected to the author's inference based on some evidence. This could imply that native speakers of Turkish have discussed the issues more elaborately in consideration of the available evidence. At least, it can be alleged that they differ from the others in use of markers of induction.

Along with the limited use of markers of induction in each database, the authors in each database avoid showing high speaker commitment by not using markers such as must, obvious, etc. For example, must is used only three times by 
native speakers of English and Turkish, which is a negligible amount. However, low commitment markers such as seem to and seem are higher in number in all three groups. It can be inferred that the authors tend to lower their commitment to the truth value of the proposition.

\subsection{Use of markers of hearsay}

\begin{tabular}{|c|c|c|c|c|c|c|}
\hline & NSEd & NSTd & WEd & $\begin{array}{c}\text { LL Ratio } \\
\text { for NSEd- } \\
\text { NSTd }\end{array}$ & $\begin{array}{c}\text { LL Ratio } \\
\text { for NSEd- } \\
\text { WEd }\end{array}$ & $\begin{array}{c}\text { LL Ratio } \\
\text { for NSTd- } \\
\text { WEd }\end{array}$ \\
\hline $\begin{array}{c}\text { Normalized } \\
\text { occurences }\end{array}$ & $\% 0.2$ & $\% 0.2$ & $\%_{0} 0.1$ & +0.05 & +6.10 & +4.45 \\
\hline
\end{tabular}

Table 6: Frequency analysis of markers of hearsay

As shown in Table 6, the non-native authors show native-like features in terms of the use of these markers. As for the Native Language/Interlanguage comparison, the non-native authors' use of markers of hearsay shows similarity with the native authors' use. As for the Interlanguage/Interlanguage comparison, as in the Native Language/Interlanguage comparison, the non-native authors have a similar use of markers of hearsay.

The use of markers of hearsay in the academic data in Chafe's (1986) study is not very frequent with the exception of citations. Even though citations are part of personal communications among academics, they are not included as markers of hearsay in Chafe's (1986: 269) study being not "usually considered hearsay evidentials". In a similar vein, citations are not included in this study as markers of hearsay due to the general view in the literature.

Hearsay is a kind of indirect evidence, the source of which is language (Chafe 1986), and which is attained through other people. According to Chafe, some of the markers of hearsay are "less direct hearsay markers" and contain "more doubtful reliability". It seems, supposed to, apparently are those markers of hearsay which downgrade the reliability of the information (ibid.: 268). Out of these, markers of people say, they say, I've been told, $X$ told me, $X$ said are more direct hearsay markers which are the ones with a high degree of reliability compared to the above-mentioned less direct hearsay markers.

Each of the three groups has similar tendencies when statistical results are taken into consideration. For example, the non-native authors show native-like features in use of these markers. Furthermore, the non-native databases do not differ from each other. They seem to share common features in use of these markers of hearsay. The results might have been different if citations had been included in the study. Citing an academic text is among the well-known aspects 
of academic discourse; however, it is different from hearsay. This is because citations are from an expert, an authority who has investigated a topic in depth and it was refereed and well-edited; while hearsay may simply be based on the observation of a single person or gossip. Therefore, citation and hearsay are very different in nature. There is quite low use of these markers in each of the three databases because the authors in academic writing abstain from using them maybe because some of them might have a negative impact on the text reliability and authorial credibility. On the other hand, as for the source of the information, the reader should assume that the knowledge conveyed through the author is reported from someone else. Namely, it is not based on the author's direct involvement in the issue. Reaching the information in that way is not a desired method in scientific texts. Hence, the use of these markers is at minimum level.

\subsection{Use of markers of deduction}

\begin{tabular}{|l|c|c|c|c|c|c|}
\hline & NSEd & NSTd & WEd & $\begin{array}{c}\text { LL Ratio } \\
\text { for NSEd- } \\
\text { NSTd }\end{array}$ & $\begin{array}{c}\text { LL Ratio } \\
\text { for NSEd- } \\
\text { WEd }\end{array}$ & $\begin{array}{c}\text { LL Ratio } \\
\text { for NSTd- } \\
\text { WEd }\end{array}$ \\
\hline $\begin{array}{c}\text { Normalized } \\
\text { occurences }\end{array}$ & $\%_{0} 5.7$ & $\%_{0} 5.4$ & $\%_{0} 4.3$ & +2.07 & $+\mathbf{4 8 . 9 8}$ & $+\mathbf{2 5 . 8 4}$ \\
\hline
\end{tabular}

Table 7: Frequency analysis of markers of deduction

Table 7 illustrates that while the NSTd shows native-like features in use of these markers, the WEd differs from the NSEd in use of markers of deduction (48.98 LL value; $p<0.0001$ ). Furthermore, the non-native authors do not seem to be very much alike ( $25.84 \mathrm{LL}$ value; $\mathrm{p}<0.0001)$. However, in each of the three databases, there is a frequent use of markers of deduction.

Chafe (1989) explains that markers of deduction denote the meaning of reasoning involving "an intuitive leap to a hypothesis from which conclusions about evidence can be deduced" (ibid.: 269). Out of these markers, can, could and would denote that the proposition consists of low degree of reliability (ibid.). Almost all of the markers of deduction in each of the three databases signal hedging, which may be as a result of the writer's opting out since they may prefer not to sound too assertive and even arrogant.

The modal verb would shows probability or possibility, low levels of assertiveness, reducing the speaker's confidence level in the proposition (Collins 2009: 142, Alonso-Almeida 2015: 45).

As far as the use of the markers of deduction is concerned, similar to that of induction, the authors avoid adopting assertive language by not using should and presumably. Oxford English Dictionary Online (2018) defines presumably 
as "used to convey that what is asserted is very likely though not known for certain". Thus, presumably is an adverb that marks high commitment on the part of the author and is avoided in their academic texts. In each database, the authors tend to use deduction markers such as can, could and would, which mark low speaker commitment to what is being said.

A couple of reasons would be offered for why they are frequently used in the academic genre.

Firstly, the source of the information is hypothesis in deduction (Chafe 1986). It can be suggested that hypothesis as a source of knowledge coincides with the nature of scientific research. The author deduces information/knowledge based on some hypotheses. The process of making a deduction is completed as a result of hypothesis formation. In academic writing, especially in theses, the researcher formulates some hypotheses at the very beginning of the study. The accuracy of these hypotheses is checked at the end as a process of scientific research.

Secondly, in the present study, the discussion sections of the dissertations are used as data and the authors discuss results and the possible reasons of their findings.

Thirdly, the use of markers of deduction includes the audience in discussion while toning the author's proposition down. In other words, deduced knowledge both lowers the reliability of the authors, conveys a low degree of commitment to the validity of the proposition and gives the readers an opportunity to evaluate what is proposed by the author. For example, the following two propositions are strictly different from each other.

(6) Consuming too much salt is the reason for high blood pressure.

(7) Consuming too much salt would be the reason for the high blood pressure.

In (6), the author shares a truth by using the copula to be. However, in (7), the author conveys hypothetical knowledge by would. Even though, in the first proposition, the rate of reliability of the author is at maximum level, it prevents the audience from taking participation in the discussion, namely prevents them thinking about some other potential reasons. Contrary to (6), in (7) the author invites the reader to get involved in the discussion, which causes active participation of the readers. Furthermore, the claim made by the author may depend on various environmental factors, not every variable can be successfully controlled.

Some possible explanations can be given also for the authors' tendency to use markers denoting a low degree of reliability and to convey a low degree of commitment to the validity of the proposition. The data of the present study 
consists of dissertation discussions reflecting the conventions of academic writing (Hyland 2005a, 2011, among others), although there may be differences in academic writing conventions (Duszak 1997). Academic texts provide ideas that are falsifiable by the very nature of scientific research. According to Meyer (1997: 21), the stronger the commitment of the author is, the easier it is to falsify the claims made by the author. Less commitment makes propositions in academic texts more difficult to rebut. Paradoxically, less commitment in academic texts makes the claims stronger due to their resistance to refutability. After all, academic texts are structured for persuading their readers by providing convincing ideas. Less commitment of the author may, for these reasons, have a more persuasive effect.

Furthermore, in line with these conventions of academic writing, authors discuss results, associate them with theories and facts, make deduction based on logical reasoning, offer potential reasons and conclusions, etc. Throughout this process, academic writing requires authors to prefer to use tentative language rather than more assertive language. The analysis of the present data indicates that the authors make use of indirect evidence, such as inferences, deductions, providing suggestions based on observation. As a result, the language they use tends to be tentative rather than conclusively irrefutable. However, this would be due to the social communication between the authors and readers. The authors may abstain from using assertive language to keep the peace with the audience. Semantic analyses of the present data indicate that the authors mostly have indirect evidence; consequently, their rate of reliability in the text is low.

Brown and Levinson's (1987) politeness theory would appear as an underlying pragmatic function of epistemic modality to make sense of the interpersonal relationship between authors and readers. Brown and Levinson assert an abstract term of 'negative face' as "the want of every competent adult member that his actions be unimpeded by others" (ibid.: 62). Some kinds of acts on the part of the speaker come into conflict with the wants of the hearer, which are called face-threatening acts. Speaker's orders, requests, suggestions, or advice putting pressure on the hearer and directing him/her to do something are the examples of the face-threatening acts which threaten the hearer's negative face wants (ibid.: 65-66). The speakers perform some kinds of politeness strategies to prevent the occurrence of face-threatening acts. Brown and Levinson claim that negative politeness strategy is one of these strategies in which the speaker "recognizes and respects the addressee's negative face wants and will not (or will only minimally) interfere with the addressee's freedom of action" (ibid.: 70). Use of hedges and avoidance of coercing hearers into doing something are the strategies the speakers perform to show negative politeness (ibid.: 145-172). 
In the present study, the authors tend to avoid face-threatening acts by using tentative language in their discussion sections. The use of assertive language may give offence to the readers and may lead them to think as if they were obliged to be in agreement with the authors, which threatens the negative face of the readers, namely, damages their right of "freedom from imposition" (Brown \& Levinson 1987: 61). As Hyland (1998: 350) suggests, firm assertions may turn into face-threatening acts which have a potential for putting the social interaction between authors and readers into jeopardy. To prevent a possible disharmony in interaction, the authors abstain from sounding like an impolite person and do not cause annoyance on the part of the reader by not boosting the tone of their statement.

Vassileva (1997: 205) emphasizes that "hedging reflects the relation between the writer and the reader, not between the writer and the proposition (or the degree of possibility/probability of the statement)". She refers to the function of hedging markers instead of what they denote in the text. In the light of her explanation, in the present study, the authors avoid high speaker commitment by using tentative language in their discussion to preserve their relationship with the audience.

Hyland (1998: 349) underlines that "academics gain acceptance for their research claims by balancing conviction with caution, either investing statements with the confidence of reliable knowledge, or with tentativeness to reflect uncertainty or appropriate social interactions". According to him, hedges and boosters not only convey the rate of reliability the authors possess but also reflect the stance they maintain against the audience (ibid.: 350). Similarly, Gao (2012: 360) suggests that the use of these markers shows "how writers position themselves, what kind of relation they wish to construct by using certain discourse markers, what kind of tone they prefer to set and what type of discourse community they would like to construct with their own effort". These markers have a function to regulate the interaction between authors and audience. As Hyland and Milton (1997: 185) suggest, the use of tentative language helps authors to "open discussion". That is to say, by mitigating the strength in their propositions, authors provide audience with an opportunity to include in discussion and express an opinion on the issue. Kreutz and Harres (1997: 184) explain the use of hedges as "the need for interaction, the inclusion of the reader in the process of reading and writing". According to them, "this type of discourse is, to some extent, more collaborative" (ibid.: 184). In the academic field, especially in scientific journals, 'letter to the editor' and 'reply to the author' are the product of interpersonal communication for which tentative language paves the way. On the other hand, boosting the propositions or using 
firm assertions causes audience to presume the author adopts an arrogant attitude towards them, which both includes one-way transmission of knowledge and eliminates the chance of exchange of views between the author and audience.

\subsection{Use of markers of sensory evidence}

\begin{tabular}{|c|c|c|c|c|c|c|}
\hline & NSEd & NSTd & WEd & $\begin{array}{c}\text { LL Ratio } \\
\text { for NSEd- } \\
\text { NSTd }\end{array}$ & $\begin{array}{c}\text { LL Ratio } \\
\text { for NSEd- } \\
\text { WEd }\end{array}$ & $\begin{array}{c}\text { LL Ratio } \\
\text { for NSTd- } \\
\text { WEd }\end{array}$ \\
\hline $\begin{array}{c}\text { Normalized } \\
\text { occurences }\end{array}$ & $\% 0.1$ & $\% 0.0$ & $\%_{0} 0.0$ & +14.86 & $+\mathbf{1 5 . 5 6}$ & -0.56 \\
\hline
\end{tabular}

Table 8: Frequency analysis of markers of sensory evidence

As illustrated in Table 8, in terms of the Native Language/Interlanguage comparison, the NST authors show native-like features in terms of the use of markers of sensory evidence. Their use of markers of sensory evidence shows similarity with the native authors' use of these markers. However, the authors in the WEd show different characteristics from the native authors (15.56 LL). As for the Interlanguage/Interlanguage comparison, the non-native databases share common features - they highly resemble each other with regard to the use of these markers.

As underlined in Chafe (1986), I see, I hear, I feel, It tastes are markers of sensory evidence denoting a high degree of reliability; however, looks like, sounds like, feels like, smells like downgrade the rate of reliability on the proposition. The use of markers of sensory evidence in the overall data is really very limited in each of the three databases. Most of them seem to denote a lesser degree of reliability.

The use of these markers requires direct involvement of the author to the issue. For example, in order to be able to write I see, the author has to see; or to write $I$ hear, s/he has to hear. Based on the present data, the use of these markers is applicable to neither discussion parts nor social/educational sciences. They seem that they are suitable for using in experiment-based studies in hard sciences. In these studies, direct involvement of the author provides the discussion of the issue with more frequent markers of sensory evidence. As Hedges (1987: 452) underlines in his distinguishing work, "the most immediately obvious difference between measurements in the physical sciences and those in the social sciences does seem to be that measurements in the physical sciences are much more accurate". The researchers' discussion is based on the findings; and to what extent the researchers are certain about their discussion is based on to what extent the findings are attained in an accurate way. Methodological 
differences providing researchers with data have a first-hand impact on the way the researchers sound un/certain. As such, Storer (1967: 78) proposes that "the use of mathematics in a science provides a greater degree of precision in organizing its body of knowledge and, thus, a "tougher" set of criteria for the evaluation of new contributions". Some kinds of features such as mathematical analyses in consequence of laboratory experiments, clinical tests which are special to the methodology of hard sciences, beyond any doubt, direct researchers to very exact results; and correspondingly, researchers express themselves in a way more free from ambiguity because the results found are based on the sensory evidence.

5.8 Use of markers of matching knowledge against verbal resources

\begin{tabular}{|c|c|c|c|c|c|c|}
\hline & NSEd & NSTd & WEd & $\begin{array}{c}\text { LL Ratio } \\
\text { for NSEd- } \\
\text { NSTd }\end{array}$ & $\begin{array}{c}\text { LL Ratio } \\
\text { for NSEd- } \\
\text { WEd }\end{array}$ & $\begin{array}{c}\text { LL Ratio } \\
\text { for NSTd- } \\
\text { WEd }\end{array}$ \\
\hline $\begin{array}{c}\text { Normalized } \\
\text { occurences }\end{array}$ & $\% 0.1$ & $\% 0.2$ & $\% 0.1$ & -10.29 & +0.17 & $+\mathbf{1 5 . 7 9}$ \\
\hline
\end{tabular}

Table 9: Frequency analysis of markers of matching knowledge against verbal resources

Table 9 shows that with regard to the Native Language/Interlanguage comparison, the non-native databases show native-like features in terms of the use of these markers. As for the Interlanguage/Interlanguage comparison (Granger 1998: 13-14, 2015: 8), the non-native databases differ from each other. The authors in these databases do not resemble each other in the use of these markers (15.79 LL value; $\mathrm{p}<0.0001$ ).

Each of the markers of matching knowledge against verbal resources (see Table 1) functions as an item lowering the speaker commitment in the text. Although the present data consists of lots of markers conveying that the proposition of the author is unreliable, the use of these markers is quite low in the present data. Chafe (1986) suggests that there is a process in which the information shared with the reader and the schemas in the reader's brain are matched. Each of these markers tries to adapt some information to the available schemas on the part of the reader.

\subsection{Use of markers of matching knowledge against expectations}

\begin{tabular}{|l|c|c|c|c|c|c|}
\hline & NSEd & NSTd & WEd & $\begin{array}{c}\text { LL Ratio } \\
\text { for NSEd- } \\
\text { NSTd }\end{array}$ & $\begin{array}{c}\text { LL Ratio } \\
\text { for NSEd- } \\
\text { WEd }\end{array}$ & $\begin{array}{c}\text { LL Ratio } \\
\text { for NSTd- } \\
\text { WEd }\end{array}$ \\
\hline $\begin{array}{c}\text { Normalized } \\
\text { occurences }\end{array}$ & $\%_{0} 5.9$ & $\%_{0} 4.8$ & $\%_{0} 4.3$ & $+\mathbf{1 7 . 7 1}$ & $+\mathbf{5 4 . 7 1}$ & +5.76 \\
\hline
\end{tabular}

Table 10: Frequency analysis of markers of matching knowledge against expectations 
As shown in Table 10, the authors in the non-native databases do not show native-like features in the use of these markers in academic writing (17.71 LL-54.71 LL). As for the Interlanguage/Interlanguage comparison (Granger 1998: 13-14, 2015: 8), the non-native authors' written products with regard to the use of markers of matching knowledge against expectations highly resemble each other.

In each of the three databases, the use of expectation markers is highly frequent. Chafe (1986) underlines that there is a process in which the knowledge of the speaker/writer is matched with his/her own or someone else's expectations. Therefore, these expectation markers have both functional and semantical contributions to the text. These markers function as transitions which connect one idea in the text to another. For example, in fact and actually function as additive transitions. They add additional knowledge to the proposition. On the other hand, semantically, they add mirativity to the proposition. Furthermore, while of course and nevertheless imply the concession of the author, but and however underline the conflict between the ideas. Shortly, each of them helps the author smoothly make transitions between, for example, conflicting, overlapping, surprising ideas in the text. It can be assumed that, in discussion parts of dissertations, authors would frequently use these transitions because they discuss the potential effects of some above-mentioned conflicting, overlapping or surprising ideas. In the absence of these items, both the quality of the text declines and the arrangement of the ideas gets difficult.

According to Berlin and Prieto-Mendoza (2014: 392), each of these expectation markers boosts the reliability of an author in a text. This means that authors increase the rate of their reliability in a text through these markers. Thus, increasing the credibility of authors' ideas, these markers would help authors leave a positive impression on the reader.

\section{Conclusion}

Contrastive interlanguage analysis of evidentiality sheds light on the degree of similarity in the use of evidential markers in academic writing by English native speakers and the non-native speakers with different L1 backgrounds.

This study analyzes the sections of dissertations, while many of the previous studies of the academic texts analyzed research articles. Even though dissertations are also academic texts, they differ from research articles in terms of the scope of the content and length. Dissertations provide more data, and authors do not encounter with the restrictions on length or word count of their texts as in scientific journals, so they are not expected to fit their ideas in a predetermined template in the writing process. 
This study showed the ways in which native and non-native speakers differ in terms of the use of evidentiality. There are obvious similarities among the writers of each group, which may be due to either universal aspects of academic discourse or idiosyncratic features of each group. The similarities and differences may stem from various factors: There are almost 'universal' or well-established conventions of academic writing across the cultures as observed from the similarities among them. The differences may be due to two factors: the level of the mastery of language of the writers and the cultural differences. Writers of English academic discourse are expected to have a high mastery of the language, but still they may lack the nitty-gritty details of the language in terms of using a variety of evidential markers and the cultural background and intellectual styles of their communities of each author can be a factor of choosing the evidentiality marker. The strategies of politeness may also be a determining factor in the choice of less assertive language as discussed above.

\section{Notes}

1 The present study is based on the results of the first author's PhD dissertation.

2 Different LL values refer to different accuracy levels and different margins of error. According to the following quote, higher LL values make the difference more significant (UCREL LL Wizard 2018).

- 95 th percentile; $5 \%$ level; $\mathrm{p}<0.05$; critical value $=3.84$

- 99th percentile; $1 \%$ level; $\mathrm{p}<0.01$; critical value $=6.63$

- 99.9th percentile; $0.1 \%$ level; $\mathrm{p}<0.001$; critical value $=10.83$

- 99.99th percentile; $0.01 \%$ level; $\mathrm{p}<0.0001$; critical value $=15.13$

While from 3.84 to 6.62 LL values mean $95 \%$ accuracy and 5\% margins of error, 15.13 and above LL values imply a more accurate significance. It shows that the result is significant at $99.99 \%$ accuracy and it has a $0.01 \%$ margin of error. Rayson et al. (2004: 926) recommend the highest cut-off value at the end of the comparison of Chi-squared and Log-likelihood tests in their study by underlining that "in order to extend applicability of the frequency comparisons to expected values of 1 or more, use of the log-likelihood statistic is preferred over the chi-squared statistic, at the $0.01 \%$ level. The trade-off for corpus linguists is that the new critical value is 15.13 ".

\section{References}

Aikhenvald, A. Y. (2004) Evidentiality. New York: Oxford University Press.

Aksu-Koç, A. and Slobin, D. I. (1986) 'A psychological account of the development and use of evidentials in Turkish.' In: Chafe, W. and Nichols, J. (eds) Evidentiality: The Linguistic Coding of Epistemology. Norwood, New Jersey: Ablex. 159-167.

Aksu-Koç, A. (1988) The Acquisition of Aspect and Modality: The Case of Past Reference in Turkish. Cambridge: Cambridge University Press.

Aksu-Koç, A. (2000) 'Some aspects of the acquisition of evidentials in Turkish.' In: Johanson, L. and Utas, B. (eds) Evidentials: Turkic, Iranian and Neighbouring Languages. Berlin: de Gruyter. 15-28. 
Alonso-Almeida, F. and Cruz-Garcia, L. (2011) 'The value of may as evidential and epistemic marker in English medical abstracts.' Studia Anglica Posnaniensia 46(3), 59-73.

Alonso-Almeida, F. (2015) 'On the mitigating function of modality and evidentiality. Evidence from English and Spanish medical research papers.' Intercultural Pragmatics 12(1), 33-57.

Anderson, L. B. (1986) 'Evidentials, paths of change, and mental maps: Typologically regular asymmetries.' In: Chafe, W. and Nichols, J. (eds) Evidentiality: The Linguistic Coding of Epistemology. Norwood: Ablex. 273-312.

Auwera, J. and Plungian, V. (1998) 'Modality's semantic map.' Linguistic Typology 2, 79-124.

Aydin, Ç. and Ceci, S. J. (2009) 'Evidentiality and suggestibility: A new research venue.' In: Fitneva, S. A. and Matsui, T. (eds) Evidentiality: A Window into Language and Cognitive Development. New Directions for Child and Adolescent Development. San Francisco: Jossey-Bass. 79-93.

Bednarek, M. (2006) 'Epistemological positioning and evidentiality in English news discourse: A text-driven approach.' Text \& Talk 26(6), 635-660.

Berlin, L. N. (2008) "“I think, therefore...": Commitment in political testimony.' Journal of Language and Social Psychology 27(4), 372-383.

Berlin, L. N. and Prieto-Mendoza, A. (2014) 'Evidential embellishment in political debates during US campaigns.' Intercultural Pragmatics 11(3), 389-409.

Brown, P. and Levinson, S. C. (1987) Politeness: Some Universals in Language Usage. Cambridge: Cambridge University Press.

Chafe, W. (1986) 'Evidentiality in English conversation and academic writing.' In: Chafe, W. and Nichols, J. (eds) Evidentiality: The Linguistic Coding of Epistemology. Norwood, NJ: Ablex. 261-272.

Clark, C. (2010) 'Evidence of evidentiality in the quality press 1993 and 2005.' Corpora 5(2), 139-160.

Collins, P. (2009) Modals and Quasi-Modals in English. Amsterdam and New York: Rodopi.

Cornilie, B. (2009) 'Evidentiality and epistemic modality: On the close relationship between two different categories.' Functions of Language 16(1), 44-62.

Davis, C., Potts, C. and Speas, M. (2007) 'The pragmatic values of evidential sentences.' In: Gibson, M. and Friedman, T. (eds) Proceedings of SALT 17. Ithaca, NY: CLC Publications.

De Haan, F. (1999) 'Evidentiality and epistemic modality: Setting boundaries.' Southwest Journal of Linguistics 18, 83-101.

Dendale, P. and Tasmowski, L. (2001) 'Introduction: Evidentiality and related notions.' Journal of Pragmatics 33, 339-348.

Duszak, A. (ed.) (1997) Culture and Styles of Academic Discourse. Vol. 104. Berlin: Walter de Gruyter.

Faller, M. T. (2002) Semantics and Pragmatics of Evidentials in Cuzco Quechua. Unpublished $\mathrm{PhD}$ dissertation. Stanford: Stanford University.

Fetzer, A. (2014) 'Foregrounding evidentiality in (English) academic discourse: Patterned co-occurrences of the sensory perception verbs seem and appear.' Intercultural Pragmatics 11(3), 333-355.

Fetzer, A. and Oishi, E. (2014) 'Evidentiality in discourse.' Intercultural Pragmatics $11(3), 321-332$. 
Fitneva, S. A. (2008) 'The role of evidentiality in Bulgarian children's reliability judgments.' Journal of Child Language 35, 845-868.

Gao, Q. (2012) 'Interpersonal functions of epistemic modality in academic English writing.' Chinese Journal of Applied Linguistics 35(3), 352-364.

Goddard, P. E. (1911) 'Athapascan (Hupa).' In: Boas, F. (ed.) Handbook of American Indian Languages. Part 1. Washington, DC: Government Printing Office. 91-158.

Granger, S. (1996) 'From CA to CIA and back: An integrated approach to computerized bilingual and learner corpora.' In: Aijmer, K., Altenberg, B. and Johansson, M. (eds) Languages in Contrast. Lund: Lund University Press. 37-51.

Granger, S. (1998) 'The computer learner corpus: A versatile new source of data for SLA research.' In: Granger, S. (ed.) Learner English on Computer. NY: Longman.

Granger, S. (2015) 'Contrastive interlanguage analysis.' International Journal of Learner Corpus Research 1(1), 7-24.

Hassler, G. (2015) 'Evidentiality and the expression of speaker's stance in Romance languages and German.' Discourse Studies 17(2), 182-209.

Hedges, L. V. (1987) 'How hard is hard science, how soft is soft science?: The empirical cumulativeness of research.' American Psychological Association 42(2), 443-455.

Hsieh, C. L. (2008) 'Evidentiality in Chinese newspaper reports: Subjectivity/objectivity as a factor.' Discourse Studies 10(2), 205-229.

Hyland, K. (1998) 'Boosting, hedging and the negotiation of academic knowledge.' Text $18(3), 349-382$.

Hyland, K. (2005a) Metadiscourse: Exploring Interaction in Writing. New York: Continuum.

Hyland, K. (2005b) 'Stance and engagement: A model of interaction in academic discourse.' Discourse Studies 7(2), 173-192.

Hyland, K. (2011) 'Academic discourse.' In: Hyland, K. and Paltridge, B. (eds) Continuum Companion to Discourse Analysis. London: Bloomsbury Publishing. 171-184.

Hyland, K. and Milton, J. (1997) 'Qualification and certainty in L1 and L2 students' writing.' Journal of Second Language Writing 6(2), 183-205.

Ifantidou, E. (2001) Evidentials and Relevance. Amsterdam: John Benjamins.

Ifantidou, E. (2005) 'Pragmatics, cognition and asymmetrically acquired evidentials.' Pragmatics 15(4), 369-394.

Jeschull, L. and Roeper, T. (2009) 'Evidentiality vs. certainty: Do children trust their minds more than their eyes?' In: Crawford, J., Otaki, K. and Takahashi, M. (eds) Proceedings of the 3rd Conference on Generative Approaches to Language Acquisition North America (GALANA 2008). Somerville: Cascadilla Proceedings Project. 107-115.

Johanson, L. (2000) 'Turkic indirectives.' In: Johanson, L. and Utas, B. (eds) Evidentials: Turkic, Iranian and Neighbouring Languages. (Empirical Approaches to Language Typology, Vol. 24). Berlin: Mouton de Gruyter. 61-88.

Johanson, L. and Utas, B. (eds) (2000) Evidentials: Turkic, Iranian and Neighbouring Languages. (Empirical Approaches to Language Typology, Vol. 24). Berlin: Mouton de Gruyter.

Kim, M. S. (2005) 'Evidentiality in achieving entitlement, objectivity, and detachment in Korean conversation.' Discourse Studies 7(1), 87-108.

King, R. and Nadasdi, T. (1999) The expression of evidentiality in French-English bilingual discourse. Language in Society 28, 355-365.

Koring, L. and De Mulder, H. (2015) 'Understanding different sources of information: The acquisition of evidentiality.' Journal of Child Language 42(5), 947-968. 
Koutsantoni, D. (2005) 'Certainty across cultures: A comparison of the degree of certainty expressed by Greek and English speaking scientific authors.' Intercultural Pragmatics 2(2), 121-149.

Kreutz, H. and Harres, A. (1997) 'Some observations on the distribution and function of hedging in German and English academic writing.' In: Duszak, A. (ed.) Culture and Styles of Academic Discourse. Vol. 104. Berlin: Walter de Gruyter. 181-201.

Lee, D. (1959) Freedom and Culture. Englewood Cliffs, NJ: Prentice Hall.

Matlock, T. (1989) 'Metaphor and the grammaticalization of evidentials.' Proceedings of the Fifteenth Annual Meeting of the Berkeley Linguistics Society, 215-225.

McCready, E. and Ogata, N. (2007) 'Evidentiality, modality, and probability.' Linguist Philos 30, 147-206.

Meyer, P. G. (1997) 'Hedging strategies in written academic discourse.' In: Markkanen, R. and Schröder, H. (eds) Hedging and Discourse. Berlin: Walter de Gruyter. 21-41.

Mushin, I. (2000) 'Evidentiality and deixis in narrative retelling.' Journal of Pragmatics $32,927-957$.

Mushin, I. (2001) Evidentiality and Epistemological Stance: Narrative Retelling. Amsterdam: John Benjamins.

O’Neill, D. K. and Atance, C. M. (2000) “'Maybe my daddy give me a big piano': The development of children's use of modals to express uncertainty.' First Language 20, 29-52.

Oztürk, Ö. (2008) Acquisition of Evidentiality and Source Monitoring. Unpublished PhD Dissertation. Newark: University of Delaware.

Palmer, F. R. (2001) Mood and Modality. Cambridge: Cambridge University Press.

Plungian, V. A. (2001) 'The place of evidentiality within the universal grammatical space.' Journal of Pragmatics 33, 349-357.

Presumably. (2018) In: Oxford Learner Dictionary Online. Retrieved in January 2018 $<$ https://www.lexico.com/definition/presumably>.

Rayson, P., Berridge, D. and Francis, B. (2004) 'Extending the Cochran rule for the comparison of word frequencies between corpora.' In: Purnelle, G., Fairon, C. and Dister, A. (eds) Le Poids des Mots. Proceedings of the 7th International Conference on Statistical Analysis of Textual Data (JADT 2004), Vol. 2, Louvain-la-Neuve, Belgium (March 10-12, 2004). Louvain: Presses Universitaires de Louvain. 926-936.

Rayson, P. (2008) Log-likelihood and effect size calculator. Lancaster, England: Lancaster University. Available from $<$ http://ucrel.lancs.ac.uk/llwizard.html $>$.

Rett, J. and Hyams, N. (2014) 'The acquisition of syntactically encoded evidentiality.' Language Acquisition 21(2), 173-198.

Sbisa, M. (2014) 'Evidentiality and illocution.' Intercultural Pragmatics 11(3), 463-483.

Storer, N. W. (1967) 'The hard sciences and the soft: Some sociological observations.' Bulletin of the Medical Library Association 55, 75-84.

Vassileva, I. (1997) 'Hedging in English and Bulgarian academic writing.' In: Duszak, A. (ed.) Culture and Styles of Academic Discourse. Vol. 104. Berlin: Walter de Gruyter. 203-221.

Yang, L. (2012) 'A comparative study of evidentiality in RAs in applied linguistics written by NS and Chinese writers.' Open Journal of Modern Linguistics 2(4), 140-146.

Yang, L. (2013) 'Evaluative functions of reporting evidentials in English research articles of applied linguistics.' Open Journal of Modern Linguistics 3(2), 119-126.

Yang, L. (2014) 'Evidentiality in English research articles of applied linguistics: From the perspective of metadiscourse.' Journal of Language Teaching and Research 5(3), 581-591. 
Mustafa Yildiz is Assistant Professor in the ELT Department at Sinop University, Turkey. His research interests focus on psychological aspects of language.

Address: Mustafa Yildiz, Department of English Language Teaching, Faculty of Education, Sinop University, 57000 Sinop, Turkey. [e-mail: mustafayildiz@, sinop.edu.tr]

Ümit Deniz Turan is Professor of Linguistics at Anadolu University, Eskişehir, Turkey. She is interested in syntax/pragmatics interaction as well as discourse analysis. She teaches linguistics courses at Anadolu University at graduate and undergraduate levels. She co-edits the Journal of Linguistics Research.

Address: Ümit Deniz Turan, Department of English Language Teaching, Faculty of Education, Anadolu University, 26470 Eskişehir, Turkey. [e-mail: udturan@ anadolu.edu.tr] 